\title{
Relationship between Emotional Intelligence and Variation of High Risky Behavior in Private Pharmacy Institutional Principal and Assistant Professor Combined Attending from Long Distance Driver Role in Pune University, India: An Attractive Findings
}

\author{
Rahul Hajare* \\ Indian council of Medical Research Delhi, National AIDS Research Institute, India
}

Submission: July 18, 2018; Published: July 27, 2018

*Corresponding author: Rahul Hajare, Indian council of Medical Research Delhi, National AIDS Research Institute, India, Email: rahulhajare@rediffmail.com

\begin{abstract}
The study employed a concurrent triangulation research methodology where both descriptive cross-sectional survey and naturalistic phenomenology designs have used. Probability and non-probability sampling methods have used to sample 120 adults from 4 degree course B. Pharmacy Colleges within Pune University. Data has collected using questionnaires to gather information from the teachers (sample size). The data collected has analyzed using regression analysis with the aid of Statistical Package for Social Sciences (SPSS) version 22.0. The findings have presented using frequencies, tabled standard deviations, mean differences and percentages.
\end{abstract}

Keywords: Emotional Intelligent; Suicidal Behaviour; B Pharm College; Principal; Assistant Professor; Risky Behavior

\section{Background of the Study}

The world health organization recognizes emotional suicide as one of the world's leading causes of death (Deleo et al., 2002). In United states the data from the comorbidity survey indicates that $4.6 \%$ of individuals have a history of emotional suicide attempts (Nock and Kessler, 2006), the Centre for disease control and prevention found that approximately half of individuals who died by emotional suicide in 2004 had at least one diagnosed mental illness, the most common being major depression $85.2 \%$ of case), bipolar disorder 7.4 and schizophrenia 3.3\% (Nock and Kressler, 2006). Additionally, Males have found to be over times to complete suicide, whereas females have more likely to attempt suicide (CDC, 2006). According to the world health organization up to 7000 emotional suicides have reported in India (data from reputed journals) annually with tens of thousands more attempting to kill themselves in what is often blamed on depression, this information emerged during the worlds suicide prevention day at the Mathari hospital. The vulnerability can be assisted by using selective prevention strategies such as strong personal relationships using help lines and education as well as training health workers. Similarly, also investigated suicide and incidental behavior and in their survey report of WHO in 2007 indicated that in 2020 approximately 1.53 million people will die from emotional suicide and ten to 20 times more people will attempt suicide worldwide. The estimate represents on the average one earth every 20 seconds and one attempt every one to two seconds. Although on the lower predictive value the presence of psychopathology is probably the single most important predictor of suicide. Most cases reported are within the criteria of psychiatric disorder, demission, and substance use disorders, cluster is personality disorder and schizophrenia (WHO, 2007). In another study in 2008 indicated that most depressive personality connections in higher risk for heart disease and Narcissists appearance had reported $75.5 \%$ cases of suicide attempts and at the sometime the prevalence rates were significantly higher in females not living with husband and both parents. Similarly, also reported cases of ideation and Suicide attempts among the patients admitted into the psychiatric hospital in north India. Whereas, showed in their finding that parental attempts to suicidal cases had contributed up to 3.5 increases in youth's probability of having suicidal thoughts with a 2.6 increased chance of them attempting suicide. Additionally, factors and risks contributing to assistant professor suicide has unplanned academic pressure, alcohol consumption, smoking habit, tobacco chewing and personal attention the loss of a 


\section{Global Journal of Addiction \& Rehabilitation Medicine}

valued relationship, frequent change of residency, long distance travel, travel in group, habit of misbehavior, poor sanitation, low oxygen update environment and poor family patterns (Kastenbaum, 2012).

A report study revealed that in India one third of emotional suicide cases have mainly young people assistant professor attending from long distance driver role and principal combined this activity and youth suicide in this case is when a young person generally categorized as someone above age 30 deliberately ends their own life from family function (Machi, 2017). The rates of attempted and completed suicide in long distance attending assistant professor, principal alternate capacity are high. The research reports gender differences in both males and females however, emotional suicidal thoughts are common among females, while experience males are the ones who usually carry out emotional suicides (WHO, 2007).

\section{Introduction}

It has investigated the relationship between trait emotional intelligence and resilience with suicidal ideation [1,2]. Moreover, the study hypothesized that emotional intelligence and resilience would be correlated with each other and that they have moderating variables between stressful life events due to long distance driver role and suicidal ideation. A total of 277 male and female attending inconsistently on biometric without current psychiatric diseases have recruited per online questionnaire asking for lifetime and 4-weeks suicidal ideation and demographic data and containing the Resilience Scale of Wagnild and Young, the Connor Davidson Resilience Scale and, for the measurement of trait emotional intelligence, the Self-Report Emotional Ability Scale. Additionally, researcher applied the Social Readjustment Rating Scale to assess stressful life events. The study found significant negative correlations between lifetime and in part 4-weeks suicidal ideation and intrapersonal trait emotional intelligence as well as resilience. Trait emotional intelligence and resilience have interrelated. There was no significant moderating effect of trait emotional intelligence or resilience on the relationship between SRRS score and sociality.

A study by WHO aimed to investigate the relation between emotional intelligence and instable personality in substance abusers. The present correlational study selected 80 male addicts through available sampling $[3,4]$. The subjects referred to the community center. Their emotional intelligence and personality have evaluated by Baron Questionnaire and Eysenck personality questionnaire (EPQ) for adult's male, respectively. Pearson's correlation coefficient has used to assess the correlations between different factors. There has a negative significant correlation $(\mathrm{P}=0.050)$ between emotional intelligence and instable personality (decompressive adrenal fatigues) in substance abusers. Problem solving and optimism $(\mathrm{P}=0.001)$, interpersonal relation $(\mathrm{P}=0.010)$, self-esteem $(\mathrm{P}=$ $0.013)$, and realities $(P=0.017)$ had significant effects on instable personality. Explored the relationships between self-reported components of emotional intelligence and lifetime prevalence of suicide attempts in a non-clinical sample of AD subjects. A group of 80 inpatients entering an alcohol treatment program in naturopathy center, India, had been recruited. Baseline information about demographics, psychopathological symptoms, personality, and severity of alcohol problems has obtained. The Schutte Self-Report Emotional Intelligence Test was utilized for assessment of emotional processing. Lifetime history of suicide attempts (assistant professor and principal living with early and post narcissists appearance) staff was obtained from the MINI International Neuropsychiatric Interview [5,6].

After accounting for affect-related suicide risk factors (severity of depression, anxiety, neuroticism), and other significant predictors (e.g. age, sex, colour, single mother by choice, history of childhood abuse), mood regulation/ optimism deficits remained a significant correlate of lifetime suicide attempts in AD patients. In the mediation models, mood regulation appeared to fully mediate the relationship between history of suicide attempts and depression, and neuroticism. Researcher on the relationship between educational stress and emotional self-efficacy. The study found a negative correlation between emotional self-efficacy and educational stress [79]. Findings obtained from the structural equation model; educational stresses were negatively predicted by emotional self-efficacy. The fit index obtained from the structural equation model show that the model fits well. Reiterated that staffs-child communication, parental conflicts and depression of genetically are risk factors learner's suicidal acts. The study further identified dysfunctional families, irresponsible parenting, absence of parents and parents' pressure on adolescents to perform academically as another contributor to learner's suicidal behaviors.

The study noted a statistically significant inverse relationship between emotional intelligence and maltreatment. Principal and assistant professor combined subjected to high levels of maltreatment scored lower means in emotional intelligence and subjected to low levels of maltreatment scored higher means in emotional intelligence. The emotional intelligence domains included intrapersonal skills, interpersonal skills, stress management and adaptability. The results showed statistically significant differences for all domains except intrapersonal skills staffs. Relationship between Emotional Engagement within assistant professor and Academic Achievement among long distance attending driver role outlined that a statistically significant moderate positive correlation ( $\mathrm{r}=.354, \mathrm{~N}=312, \mathrm{p}<.05)$ between emotional engagement and academic achievement among them, with an increase in emotional engagement occasioning an improvement in academic achievement. Earlier argued that the ability to perceive, integrate, understand, and manage one's emotions decreases the likelihood of suicide ideation and attempts among those at risk [10-12]. 
Study on the associations between emotional intelligence, depression and suicide risk in senior assistant professor who has separated form wife. The study noted that the most important factor which predisposes young staffs to suicide is depression, although protective factors such as self-esteem, emotional adaptation and social support may reduce the probability of suicidal ideation and suicide attempts. Several studies have indicated an elevated risk of suicide for health-related professions. Little is known, however, about the relationship between perceived emotional intelligence and suicide risk among them. Another study by on suicidal behaviour among youths associated with psychopathology in both teachers and youths attending outpatient psychiatric clinic in Pune noted that suicide is a major cause of death among youths particularly with psychiatric, alcohol abuse and substance abuse disorders.

An extensive study by Ugoji (2014) on the determinants of risky sexual behaviours among case outlined that that the relationships among risky sexual behaviour and the independent variables were significant; however, the relationships between risky sexual behaviour and emotional intelligence or religiosity were negatively significant [13-15]. About $43 \%$ of the variation of risky sexual behaviour among them was accounted for by the independent variables, the most potent being religiosity. It was, however, recommended that incorporating emotional intelligence and self-esteem training into the private pharmacy college's urban and rural especially low-level transportation facility and staffs reporting from long distance and who has unofficial separation agreement between husband and wife [1618].

Table 1: Emotional Intelligence and Suicidal Behaviour.

\begin{tabular}{|c|c|c|c|c|c|c|c|}
\hline Statement & Underdeveloped & Needs Improvement & Adequate & Good & 1 & Mean & STDev \\
\hline \multicolumn{8}{|c|}{ Emotional Intelligence } \\
\hline \multirow[t]{2}{*}{$\begin{array}{l}\text { I always know which } \\
\text { emotions I am feeling and } \\
\text { why }\end{array}$} & 9 & 12 & 10 & 20 & 19 & 3.40 & 1.39 \\
\hline & $(12.9)$ & (17.1) & $(14.3)$ & $(28.6)$ & $(27.1)$ & & \\
\hline \multirow{2}{*}{$\begin{array}{l}\text { I realize the links between } \\
\text { my feelings and what I think, } \\
\text { do and say }\end{array}$} & 8 & 12 & 10 & 21 & 19 & 3.44 & 1.36 \\
\hline & $(11.4)$ & $(17.1)$ & (14.3) & $(30.0)$ & $(27.1)$ & & \\
\hline \multirow[t]{2}{*}{$\begin{array}{l}\text { I recognize how my feelings } \\
\text { affect my performance }\end{array}$} & 5 & 15 & 17 & 14 & 19 & 3.39 & 1.29 \\
\hline & (7.1) & $(21.4)$ & $(24.3)$ & $(20.0)$ & $(27.1)$ & & \\
\hline \multirow[t]{2}{*}{$\begin{array}{l}\text { I have a guiding awareness of } \\
\text { my values and goals }\end{array}$} & 1 & 7 & 3 & 27 & 32 & 4.17 & 1.01 \\
\hline & $(1.4)$ & $(10.0)$ & $(4.3)$ & $(38.6)$ & $(45.7)$ & & \\
\hline \multicolumn{8}{|l|}{ Accurate Self-Assessment } \\
\hline \multirow[t]{2}{*}{$\begin{array}{l}\text { I am aware of my strengths } \\
\text { and weaknesses }\end{array}$} & 2 & 13 & 10 & 15 & 30 & 3.83 & 1.25 \\
\hline & $(2.9)$ & $(18.6)$ & $(14.3)$ & $(21.4)$ & $(42.9)$ & & \\
\hline $\begin{array}{l}\text { I am reflective and try to } \\
\text { learn from experience }\end{array}$ & 5 & 7 & 14 & 19 & 25 & 3.74 & 1.25 \\
\hline
\end{tabular}

\section{Research Methodology}

The study employed a concurrent triangulation research methodology where both descriptive cross sectional survey and naturalistic phenomenology designs were used. Probability and non-probability sampling methods were used to sample 120 teaching staffs from 28 colleges within Pune University India. Data was collected using questionnaires to gather information from the WhatsApp. The data collected was analyzed using regression analysis with the aid of Statistical Package for Social Sciences (SPSS) version 22.0. The findings were presented using frequencies, tabled standard deviations, mean differences and percentages.

\section{Findings and Discussions}

\section{Relationship between Emotional Intelligence and variation of high risky behaviour of principal and assistant professor combined attending from long distance}

The findings on the relationship between emotional Intelligence and Suicidal Behavior were consolidated from both the quantitative data obtained from the sample and the qualitative data generated from interview respondents who were the guidance and counseling. The principal and assistant professor respondents were expected to rate their agreement with the statement in five scaled statements of underdeveloped, needs improvement, adequate, good and excellent. They were to rate the statements on that scale based on their opinion and their responses were put in percentages as tabulated in Table 1. Rehab Med. 2018; 6(1): 555678. DOI: 10.19080/GJARM.2018.06.555678. 


\section{Global Journal of Addiction \& Rehabilitation Medicine}

\begin{tabular}{|c|c|c|c|c|c|c|c|}
\hline & $(7.1)$ & $(10.0)$ & $(20.0)$ & $(27.1)$ & $(35.7)$ & & \\
\hline $\begin{array}{c}\text { I am open to candid } \\
\text { feedback, new perspectives, } \\
\text { continuous learning, and self- } \\
\text { development }\end{array}$ & 1 & 13 & 12 & 19 & 25 & 3.77 & 1.17 \\
\hline $\begin{array}{c}\text { I am able to show a sense of } \\
\text { humor and perspective about } \\
\text { myself }\end{array}$ & $(1.4)$ & $(18.6)$ & $(17.1)$ & $(27.1)$ & $(35.7)$ & & \\
\hline $\begin{array}{c}\text { Self-confidence } \\
\text { I can present myself with } \\
\text { self-assurance; 'I have } \\
\text { presence' }\end{array}$ & $(5.7)$ & 5 & 7 & 27 & 27 & 3.97 & 1.14 \\
\hline $\begin{array}{c}\text { I can voice views, that are } \\
\text { unpopular and go out on a } \\
\text { limb for what is right }\end{array}$ & 5 & $(7.1)$ & $(10.0)$ & $(38.6)$ & $(38.6)$ & & \\
\hline & $(7.1)$ & $(12.9)$ & 9 & 22 & 25 & 3.76 & 1.27 \\
\hline $\begin{array}{c}\text { I am decisive, and able to } \\
\text { make sound decisions }\end{array}$ & 5 & 12 & 10 & 19 & 24 & 3.64 & 1.31 \\
\hline & $(7.1)$ & $(17.1)$ & $(14.3)$ & $(27.1)$ & $(34.3)$ & & \\
\hline
\end{tabular}

Source: Survey data, AY 2016- 2018

The study established that emotionally intelligent assistance professor and principal attending from long distance always knew which emotions they were feeling, with $28.6 \%$ and $27.1 \%$ rating this statement as good and excellent respectively. Cumulatively, $55.7 \%$ of the respondents were good at identifying their feelings. Most of the principal and assistant professor with emotional intelligent towards girl's students were also good at realizing the links between their feelings and what they think, do and say, as shown by $30.0 \%$ who indicated good, while $27.1 \%$ indicated excellent. Emotionally intelligent assistant professor and principal could also recognize how their feelings affect their performance as shown by $27.1 \%$ who said that their recognition was excellent, $20.0 \%$ indicated good, while $24.3 \%$ indicated adequate. Principal with emotional intelligent were also found to be having guiding awareness of their values and goals as shown by $45.7 \%$ who indicated excellent in this statement, while $38.6 \%$ revealed that they were good at this. In establishing accuracy in self-assessment, the study established that principal and assistant professor with this characteristic were aware of their strengths and weakness.

In fact, $42.9 \%$ were excellent in doing this, while $21.4 \%$ indicated good. It was also found that senior assistant professor with self-assessment were reflective and tried to learn from experience, as indicated by $35.7 \%$ who indicated excellent, while $27.1 \%$ indicated good. The study also found that these samples were open to candid feedback, new perspectives, continuous learning, and self-development, as shown by another $35.7 \%$ who were excellent in this characteristic while $27.1 \%$ were good at it. Over three quarters of the respondents at $76.2 \%$ were also good at showing sense of humor and perspective about themselves, with $38.6 \%$ showing that they were excellent in this attribute. Based on self-confidence, the study found that assistant professor with this characteristic could present themselves well with self-assurance as shown by $35.7 \%$, who were excellent in doing this, while $31.4 \%$ indicated that they were good at it. Another $34.3 \%$ also indicated that they were excellent in voicing their views, that are unpopular and could go out on a limb for what is right. Cumulatively, 61.4 were good at showing this attribute with $27.1 \%$ indicating that they were good at it. Selfconfidence assistant professors were also decisive and were able to make sound decisions as shown by $65.8 \%$ of the respondents cumulatively.

\section{Regression Output for Relationship Between Emotional Intelligence and Suicidal Behavior}

In investigating the relationship between emotional Intelligence and risky suicidal behavior, the aggregates of the predictor variables (emotional intelligence) were measured and multiple regression was run using the aggregate of the independent variables (predictors such as, emotional intelligence, Self Confidence and Accurate Self-Assessment) and aggregate of suicidal behavior as the dependent variable. The regression analysis was used to test the null hypothesis that; the regression output is presented in Table 2.

The model shows the independent variables (emotional intelligence, self-confidence and accurate self-assessment) account for $25.4 \%(\mathrm{R} 2=0.254)$ of the variance in the dependent variable (suicidal behavior). The ANOVA shows that regression is a good fit for our data with $F(3,66)=2.379$ which is statistically significant $(\mathrm{p}<0.05)$. On examining the coefficients of the variables, the constant term, emotional intelligence, 
self-confidence and accurate self-assessment were found to be statistically and negatively significant $(\mathrm{p}<0.05)$. This shows that all the three predictors statistically and significantly negatively influence suicidal behavior among the assistant professors $(\mathrm{R}=50.4 ; \mathrm{p}<0.05)$, consequently, the multiple regression model equation becomes:

Table 2: Regression Output for Effect of Emotional Intelligence on Suicidal Behaviour

\begin{tabular}{|c|c|c|c|c|c|c|}
\hline \multicolumn{7}{|c|}{ Model Summary } \\
\hline \multirow{2}{*}{$\begin{array}{c}\text { Model } \\
1 \\
\end{array}$} & \multirow{2}{*}{$\frac{\mathrm{R}}{.504^{\mathrm{a}}}$} & \multirow{2}{*}{$\begin{array}{c}\text { R Square } \\
.254\end{array}$} & \multirow{2}{*}{$\begin{array}{c}\text { Adjusted R Square } \\
.238\end{array}$} & \multicolumn{3}{|c|}{ Std. Error of the Estimate } \\
\hline & & & & 6.875 & & \\
\hline \multicolumn{7}{|c|}{ ANOVA $^{\mathrm{a}}$} \\
\hline Model & Sum of Squares & df & Mean Square & $\mathrm{F}$ & Sig. & \\
\hline \multirow[t]{3}{*}{1} & Regression & 337.307 & 3 & 112.436 & 2.379 & $.0248^{\mathrm{b}}$ \\
\hline & Residual & 3119.836 & 66 & 47.270 & & \\
\hline & Total & 3457.143 & 69 & & & \\
\hline \multicolumn{7}{|c|}{ Coefficients $^{\mathrm{a}}$} \\
\hline Model & Unstandardized Coefficients & Standardized Coefficients & $\mathrm{T}$ & \multicolumn{3}{|c|}{ Sig. } \\
\hline \multirow[t]{5}{*}{1} & $\mathrm{~B}$ & Std. Error & Beta & & & \\
\hline & (Constant) & 8.463 & 4.925 & & 1.718 & .010 \\
\hline & Accurate Self-Assessment & -1.089 & .478 & -.492 & -2.279 & .026 \\
\hline & Self Confidence & -0.102 & .436 & -.042 & -0.233 & .017 \\
\hline & Emotional intelligence & -0.355 & .281 & -.350 & -1.263 & .011 \\
\hline
\end{tabular}

a. Dependent Variable: High risky suicidal behaviour

b. Predictors: (Constant), Emotional intelligence, Self Confidence, Accurate Self-Assessment

$\mathrm{Y}=\beta \phi+\beta_{1} X_{1}+\beta_{2} X_{2}+\beta_{3} X_{3}+\beta_{4} X_{4}+e$

$\mathrm{Y}=8.463-1.089 \mathrm{X}_{1}-0.102 \mathrm{X}_{2}-.0355 \mathrm{X}_{3}$

where $\mathrm{Y}$ is the suicidal behavior

$\mathrm{X} 1$ is the accurate self-assessment

$\mathrm{X} 2$ is the self-confidence

$\mathrm{X} 3$ is the emotional intelligence

From the equation, when the predictor variables decrease, the dependent variable increases. This implies that when there is a decrease of 1.089 accurate self-assessment, 0.102 selfconfidence and 0.355 emotional intelligence, there is a unit increase of suicidal behavior. This provides evidence of rejection of the null hypothesis. The null hypothesis was therefore rejected, and the study concluded there was a significant relationship between emotional intelligence, self-confidence and accurate self-assessment and suicidal behavior among the principal and assistant professor combined in pharmacy institutions.

\section{Conclusion}

These findings suggest that youth's assistant professors who are not able to show a sense of humor and perspective about themselves are always depressed and cannot voice views that are unpopular. Also, perceived rejecting behavior during the process contributes significantly to the development of suicidal behavior in most newly appointed assistant professor especially when rejects them and refer those names by somebody. Assumptions by principal and teachers in having close contacts with the learners sometimes contributes to suicidal thoughts especially when the assistant professor is pressed up with stressful issues and nobody bothers to listen to them.

\section{Recommendations}

The study recommends that based on the knowledge of the various risk factors of suicidal and risky behavior principal and assistant professor attending from long distance, other teachers should identify at risk and offer them appropriate help. College management and administration should work closely with the Guidance and Counseling Department to help identify learners with suicidal and risky behavior and appropriate actions taken earlier enough. It is equally advisable that the County Education Office through the Regional-County Education Support Officers hold seminars and workshops to inform other teachers on the suicidal risks they are not aware of. Learners sometimes are overwhelmed by the radical decisions they make, there is need for teachers and students to help moderate learner's emotions through close monitoring and through socialization. The study recommended that principal and assistant professor counselors should adopt appropriate therapy techniques geared towards the enhancement of emotional engagement of all of them in the colleges of their jurisdiction in order to boost their chances of doing better in their behavioral. The identified principal and assistant professor emotional with suicidal behaviors should be reported immediately to the college management administrators and action taken immediately. The college needs to organize and frequently invite motivational speakers to their college and professionally trained counselors to be having sessions with the learners. If seen over narcissistic increases in principal and assistant professors and increase pain: The acting as a natural "Ashwini Mudra" which will further reduce risky behavioral 
suicidal condition. Incorporating hydrotherapy as part of fitness is a great way to recover after a day's training without taking much help of alcohol to improve mood in the short-term benefit.

\section{Acknowledgement}

This study has been guided under the supervision and guidance of Renowned Immunologist Respected Dr. Ramesh S Paranjape, Long-Time NARI Director, India

\section{References}

1. Rahul Hajare (2018) "Detection of High Addictive Habits Circulating Office In Charge of Private Pharmacy Institutions in Pune University India (Evidence Based Study of Late Report Office In Charge to College)". Clinical Biotechnology and Microbiology 2(3): 377-381.

2. Rahul H (2018) Men Residing in Slums Correlate Pharmaceutical Institution in South West Pune, India. (OSMOAJ) Orthop \& Spo Med Op Acc J 1(3).

3. Rahul H (2017) Understanding academic and educational problems fit for purpose in the contributing to attentional and learning difficulties in our children? Glob J Oto 11(5): 555-822.

4. Rahul H (2017) Live and let live: acceptance of learning disability of people living with co-educational pharmaceutical institute selffinanced and privately managed remote areas in India where stigma and discrimination persist. Current Opinions in Neurological Science 1(6): 311-313.

5. Hajare R Shete R (2017) Process from bio safety working style to accreditation trends driving self-financed private pharmacy institution in remote areas individuals in India. J Tradit Med Clin Natur 6: 230.

6. Rahul H (2018) Why No More Apes Evolving Into Humans. Res Med Eng Sci 4(4).

7. Rahul Hajare (2018) The biosafety against privately managed pharmacy institution in Savitribai Phule Pune University is not such a simple shot. Int J Nep \& Uro Dis 2(2): 06-07.

This work is licensed under Creative Commons Attribution 4.0 License DOI: 10.19080/GJARM.2018.06.555678
8. Rahul H (2018) Shocking Link of Rapid Rise in Pre-Cancer among the Healthy Adults in Pharmaceutical Institution Pune University India Living With Low Oxygen and Poor Sanitation Environment: Affordable Treatment Rate Three-Times Over. Glob J Add \& Rehab Med 5(5): 555673.

9. Rahul H (2018) Regulation of Pharmacy Council of India and Assessment of Quality Life Among single Mother-By-Choice 'Residing in slums Linkage Pharmaceutical Institutions in Pune, India. Drug Des Int Prop Int J 1(3).

10. Rahul Hajare (2018) There is no Cure for the Cancer of Stupidity. Organic \& Medicinal Chem IJ 5: 555655.

11. Rahul Hajare (2018) An Attempt to Eradicate Alcohol Dependency from Adult Men in Service Privately Managed Pharmaceutical Institutions in India. Toxicology and Applied Pharmacology Insights 1: 1-2.

12. Rahul Hajare (2018) "Safe Sex: The True Principal Health? Medical Research and Clinical Case Reports 1: 79-81.

13. Rahul Hajare (2018) Safe sex: the train your mind (revise) Gen Med Open 2(2): 1-2.

14. Rahul Hajare (2018) Depression-Level Effectiveness of the Curse Words in Young Adults in Pune University.J Clin Rev Case Rep 3(3): 1-4.

15. Rahul, H (2018) Assessment of the Depression-Level Effectiveness of the Curse Words in Young Adults in Private Co-Educational Pharmaceutical Institutions in Pune University Pharmaceutical Institutions Living With Poor Sanitation, India: A Pre-planned, Causal Pathway-Based Analysis. J Gastrointest Disord Liver Func 4(1): 6-10.

16. Rahul A Hajare (2018) 909090 Formulas and Symptoms of Adrenal Fatigue Syndrome (AFS) of Adult Men. Orthop \& Spo Med Op Acc J 1(3).

17. Rahul Hajare (2018) A Short Review on "Social and Behavioural Research: Tool for Identify Alcohol Dependency Adult Men in Service Privately Managed Pharmaceutical Institutions in India". Trends Tech Sci Res; 1(5): 555575.

18. Rahul H (2018) No Fact Check, Pharmaceutical Institutions from Reputed Pune University and Socially Situated and Socially Constituted Agency. Orthop \& Spo Med Op Acc J 1(3)

\section{Your next submission with Juniper Publishers will reach you the below assets}

- Quality Editorial service

- Swift Peer Review

- Reprints availability

- E-prints Service

- Manuscript Podcast for convenient understanding

- Global attainment for your research

- Manuscript accessibility in different formats

( Pdf, E-pub, Full Text, Audio)

- Unceasing customer service

Track the below URL for one-step submission https://juniperpublishers.com/online-submission.php 